\title{
Black Magic üzüm çeşidinde organik ve organomineral gübre uygulamalarının verim, kalite ve bitki beslemeye etkileri
}

The effects of organic and organomineral fertilizer applications on yield, quality and plant nutrition in Black Magic grape variety

\author{
Serkan DEMIR ${ }^{1}$ (D) Serpil TANGOLAR ${ }^{1 / \infty}$ \\ ${ }^{1}$ Çukurova University, Faculty of Agriculture, Department of Horticulture, Sarıçam-Adana, Turkey.
}

MAKALE BILGISI / ARTICLE INFO

Makale tarihçesi / Article history:

DOI: $10.37908 / \mathrm{mkutbd} .801859$

Geliş tarihi /Received:08.10.2020

Kabul tarihi/Accepted:16.12.2020

\section{Keywords:}

Grapevine, fertilization, plant nutrition, ecological viticulture.

\footnotetext{
Corresponding author: S. TANGOLAR

$\bowtie$ : stangolar@cu.edu.tr
}

Ö ZET / A B STR A C T

Atıf / Citation: Demir S, Tangolar S (2021) Black Magic üzüm çeşidinde organik ve organomineral gübre uygulamalarının
\[ \begin{array}{l}\text { verim, kalite ve bitki beslemeye etkileri. MKU. Tar. Bil. Derg. 26(1) : } 163-170 . \quad \text { DOI: } \\ 10.37908 / \text { mkutbd.801859 }\end{array} \]

\section{GiRiş}

Dünya nüfusunun hızla artması ve buna bağlı olarak insanların beslenme intiyacı, tarımda verimi arttırmak amacıyla yoğun girdi (pestisitler, gübreler, hormonlar, sulama, fosil yakıtlar vb.) kullanımına yol açmıştır. Yeşil devrimle birlikte 1960'lı yıllarda yüksek verimli tohumluklar, monokültür ve yoğun girdi kullanımıyla tarımsal üretim artmış, ancak bu uygulamalar beraberinde çevre kirliliği ve doğal dengede bozulmaları da getirmiştir. Geleneksel tarımın olumsuz etkilerini ortadan kaldıracak tarımsal üretim sistemlerine geçilmesi gerektiğinin gündeme gelmesi, organik tarım üretim sistemini ortaya çıkarmış ve geliştirmiştir (illter ve Altındişli, 1996). Diğer organik tarım alanlarında olduğu gibi bağcllıkta da sistemin önemli bileşenlerinden birisi asmaların beslenmesinde doğal kayaçlar ve bileşikler yanında, başta çiftlik gübresi ve kompost olmak üzere, asmanın budama atıklarının, yeşil gübre bitkilerinin vb. kullanılmasıdır (Rotaru ve ark. 2011; Tangolar ve ark., 2019). Ancak yapılan bazı araştırmalarda organik tarımda kullanılan bu 
materyallerle bitki beslemenin sınırlı etkisinin olduğu ve verimde bazen çok belirgin artışların olamayabileceği gösterilmiştir. Bunda organik gübrelerin içeriklerinin kullanılan ham materyale göre değişken olması yanında (Erdal, 2018) kullanılan miktarın farklı olması da etkili olmaktadır. Organik maddelerin kimyasal gübreler kadar etkili olabileceğinin gösterilmesi amacıyla birçok farklı organik materyal bağcılık araştırmalarında denenmektedir. Erdal ve ark. (2010) yaş ve kuru üzüm verim değerlerini konvansiyonel parsellerde daha yüksek bulurken, organik parsellerden elde edilen yaş ve kuru üzüm verimlerinin bölgeden elde edilen verim ortalamaları ile benzerlik gösterdiğini belirtmişlerdir. Tangolar ve ark. (2011), Adana koşullarında yaptıkları bir çalışmada yalnızca fiğ uygulaması (kontrol) dışında, çiftlik gübresi, bazaltik tüf ve çiftlik gübresi+bazaltik tüf uygulamanın, ikinci yılında çiftlik gübresi ve bazaltik tüf uygulamalarının, yalnız fiğ uygulamalarına göre incelenen özellikler üzerine bir miktar olumlu etkisi olduğu ve Ekolojik bağcılığın Adana koşullarında uygulanabilirliği bakımından olumlu bulunmuştur. Bunlara karşın, Aygün ve Özdemir (2019)'in çalışmalarında konvansiyonel bağcılıkta verim ve kalite organik yetiştiricilikten daha yüksek bulunmuştur.

Son zamanlarda organik materyallerin yarayışlığını arttırmak üzere bunlara mineral madde katkıları yapılmaktadır. Organik gübrelerde eksik görülen mineral maddelerin ilave edilmesiyle oluşturulan organomineral gübreler standart bir içeriğe sahip gübrelerdir. Organomineral gübrelerin kimyasal gübrelere en iyi alternatif olduğu birçok çalışmada gösterilmiştir (Tarakçıoğlu ve Aşkın, 2006; Pekcan ve ark., 2009; Kominko ve ark., 2016; Aslan, 2018). Bu çalışmalarda organomineral gübrelerin verim ve kalite üzerine organik gübrelerden daha çok etkili olduğu bildirilmiştir.

Organomineral gübreler, bir veya daha fazla organik maddenin bitkinin ihtiyaç duyduğu miktarda makro ve mikro besin elementi ile tepkimeye girmesi veya karışımı sonucu elde edilen gübrelerdir. Katı veya sıvı formları vardır. Bu gübreler toprak ve yapraktan uygulanabilmektedir. Organomineral gübrelerde organik madde kaynağı olarak çiftlik gübresi, kompost, atık su arıtma çamurları, leonardit, hümik asit, biyoçar ve biyogaz kullanılabilir (Süzer ve Çulhacı, 2017). Kacar ve ark. (1996) yaptıkları bir çalışmada, çay atığı, su, taze sığır, at ve tavuk gübresi, çay gübresi ve kireç katkı maddeleri karışımının fermente edilmesi sonucu organomineral gübreye dönüştüklerini ve bu materyalin etkili şekilde kullanılabileceğini belirtmişlerdir. Organomineral gübrelerin kullanıldığı çalışmalar incelendiğinde tarla (Kaptan ve Aydın, 2018; Tamer ve
Namlı, 2018) ve bahçe bitkilerinde birçok bitki türünde (Fernandes ve ark., 2003; Olaniyi ve Akanbi, 2007; Olaniyi ve ark., 2009; Pekcan ve ark., 2009; Olaniyi ve ark., 2010; Olaniyi ve Ojetayo 2011; Ojo ve ark., 2014; Dannehl ve ark., 2016; Kominko ve ark., 2016; Aslan, 2018) denendikleri ve olumlu sonuçlar alındığı saptanmıştır.

Ülkemizde organomineral gübrelerin kullanıldığı araştırmalarda, araştırmacıların organomineral gübre kaynağı olarak; ticari gübre, organik gübre ve mineral gübre karışımı yoluyla kendi formüle ettikleri organomineral gübreleri kullandıkları görülmüştür (Erdal, 2018).

Ülkemizde bağcılık alanında bu konuda yapılmış iki çalışma bulunmaktadır. Çalışmalardan birisinde organomineral gübrelerin asmanın sürgün uzunluklarında önemli farklılıklara neden olduğu belirlenmiştir (Özdemir, 2018). Özdemir ve ark. (2018)'nın başka bir çalışmasında, organik ve organomineral gübre uygulamalarının üzümde toplam fenolik, flavonoid ve antosiyanin üretimini ve antiradikal aktiviteyi olumlu yönde etkiledikleri belirlenmiştir. Bunlar dışında bağcılık alanında verim ve kalite özellikleri üzerine organomineral gübre etkisinin incelendiği bir çalışma bilgimiz dâhilinde bulunmamaktadır.

Bu çalışmanın amacı erkenci sofralık üzüm yetiştiriciliği potansiyeli yüksek olan Çukurova'da, güncel kullanımı olan organik ve organomineral sıvı gübrelerin asmalara topraktan ve yapraktan uygulanmasının verim, kalite ve bitki besleme üzerine olan etkilerini incelemektir.

\section{MATERYAL ve YÖNTEM}

\section{Materyal}

Araştırma, 2019 yılında Çukurova Üniversitesi Ziraat Fakültesi Bahçe Bitkileri Bölümü Araştırma ve Uygulama Bağında yürütülmüştür. Bitkisel materyal olarak dikim sıklığı 3.5x2 m olan, Çift Kollu Kordon şeklinde terbiye edilmiş $1103 \mathrm{P}$ (Paulsen) anacı üzerine aşılı Black Magic üzüm çeşidinin kısa budama uygulanan 4 yaşlı asmaları kullanılmıştır. Çalışmada organik (BioGas) ve organomineral (AminoSEL-K 3-0-15+ME) gübrelerin ayrı ayrı ve birlikte uygulanmasının etkileri karşılaştırılmıştır.

\section{Yöntem}

Uygulamalar, yapraktan (BioGas $400 \mathrm{cc} 100 \mathrm{~L}^{-1}$ su ve AminoSEL-K $300 \mathrm{cc} 100 \mathrm{~L}^{-1} \mathrm{su}$ ) ve topraktan (BioGas $4 \mathrm{~L}$ $\mathrm{da}^{-1}$ ve AminoSEL-K $4 \mathrm{~L} \mathrm{da}^{-1}$ ) olmak üzere iki şekilde yapılmıştır. Kontrol uygulamalarına yaprak ve topraktan yalnızca su verilmiştir. Gübreler, bitkilere sürgünler 25$30 \mathrm{~cm}$ uzunluğuna geldiğinde, tane tutumunda (saçma 
iriliği) ve iri koruk (nohut büyüklüğünde) olmak üzere üç farklı dönemde uygulanmıştır.

Uygulamaların etkisini belirlemek üzere derim zamanında verim, salkım ağırlığı, salkım uzunluğu, genişliği ve büyüklüğü ile yüz tane ağırlığı, yüz tane hacmi, tane uzunluğu, genişliği ve büyüklüğü, SÇKM, asitlik, $\mathrm{pH}$ ve olgunluk indisi özellikleri incelenmiştir. Ayrıca, bitkilerin klorofil miktarı, SPAD Metre (SPAD-502 Plus) cihazı ile tam çiçeklenme, ben düşme ve olgunluk zamanlarında sürgünün $1 / 3^{\prime}$ lük orta kısmındaki yapraklarda yapılan okumalar ile saptanmıştır. Bitki yaprak sıcaklığı $\left({ }^{\circ} \mathrm{C}\right)$, infrared termometre (ScanTemp 485) ile tam çiçeklenme, ben düşme ve olgunluk zamanında öğle saatlerinde ölçülmüştür.

Uygulamaların bitkilerin beslenmesi üzerine etkilerinin belirlenmesi amacıyla yaprak analizleri yapılmıştır. Yaprak örnekleri yıkama, kurutma ve ögütme işlemlerinden sonra kuru yakma yöntemi ile analize hazırlanmıştır. Analizler için, ben düşme döneminde salkımların karşısından alınan yaprak örneklerinde azot (N) konsantrasyonu, Bremner (1965) tarafından bildirildiği şekilde Kjeldahl; toplam fosfor (P), vanadomolibdofosforik sarı renk yöntemine göre Shimadzumodel UV 1201 spektrofotometresi kullanılarak saptanmıştır (Kacar, 1972). Yaprakların, potasyum (K) konsantrasyonu Eppendorf Elex6361 Fleymfotometresi; kalsiyum (Ca), magnezyum (Mg), demir (Fe), çinko $(\mathrm{Zn})$, mangan $(\mathrm{Mn})$ ve bakır $(\mathrm{Cu})$ konsantrasyonu ise atomik absorpsiyon spektrofotometresi yardımıyla belirlenmiştir.
Deneme iki faktörlü Tesadüf Blokları Deneme Desenine göre, 3 tekerrürlü ve her tekerrürde 3 omca olacak şekilde kurulmuştur. Denemeden elde edilen verilere JMP istatistik programı kullanılarak varyans analizi uygulanmış ve farklı grupların saptanmasında \% 5 önem seviyesinde LSD testinden yararlanılmıştır.

\section{BULGULAR ve TARTIŞMA}

\section{Üzüm verimi ile salkım, tane ve şıra özelliklerine ilişkin bulgular}

Uygulanan organik ve organomineral gübrelerin verim ile salkım ağırlığı, uzunluğu, genişliği ve büyüklüğü üzerine etkisi istatistiksel olarak önemli bulunmamıştır. Uygulama şeklinin etkisi incelendiğinde, verim, salkım ağırlı̆̆ı, salkım uzunluğu, genişliği ve büyüklüğü bakımından yapraktan (sırasıyla $8145 \mathrm{~g} \mathrm{omca}^{-1}, 407.3 \mathrm{~g}$, $19.48 \mathrm{~cm}, 14.10 \mathrm{~cm}, 274.8 \mathrm{~cm}^{2}$ ) uygulamanın, toprak (sırasıyla $6086 \mathrm{~g} \mathrm{omca}^{-1}, 304.3 \mathrm{~g}, 16.64 \mathrm{~cm}, 12.46 \mathrm{~cm}$, $208.2 \mathrm{~cm}^{2}$ ) uygulamasından daha yüksek değerler verdiği saptanmıştır (Çizelge 1). Aslan (2018) Organomineral gübre kullanımının Antepfıstığının verimi ve toprağın fiksasyon kapasitesi üzerine etkisini incelediği çalışmada, organik gübrenin, mineral gübre ile birlikte kullanılması halinde ağaç başına ortalama verimde \% 40'a varan bir artış saptamıştır. Tarakçıoğlu ve Aşkın (2006) da kivi bitkisine uyguladıkları Organomineral gübrelerin dozlarındaki artışla doğru orantılı olarak veriminde artığını belirlemişlerdir.

Çizelge 1. Organik ve organomineral gübre uygulamaların Black Magic üzüm çeşidinin verim ve salkım özellikleri üzerine etkisi

Table 1. The effect of organic and organomineral fertilizer applications on yield and cluster characteristics of Black Magic grape variety

\begin{tabular}{|c|c|c|c|c|c|}
\hline Uygulama & $\begin{array}{l}\text { Verim } \\
\left.\text { (g omca-1) }^{-1}\right)\end{array}$ & $\begin{array}{l}\text { Salkım } \\
\text { Ağırlığı } \\
\text { (g) }\end{array}$ & $\begin{array}{l}\text { Salkım } \\
\text { Uzunluğu } \\
(\mathrm{cm})\end{array}$ & $\begin{array}{l}\text { Salkım } \\
\text { Genişliği } \\
(\mathrm{cm})\end{array}$ & $\begin{array}{l}\text { Salkım } \\
\text { Büyüklüğü }\end{array}$ \\
\hline \multicolumn{6}{|l|}{ Gübre } \\
\hline Kontrol & 7242 & 362.1 & 18.47 & 13.49 & 248.6 \\
\hline Organik & 7534 & 376.7 & 18.50 & 13.77 & 256.1 \\
\hline Organomineral & 6718 & 335.9 & 17.89 & 12.83 & 231.5 \\
\hline Organik+Organomineral & 6971 & 348.6 & 17.37 & 13.03 & 229.7 \\
\hline LSD \%5 & Ö.D. & Ö.D. & Ö.D. & Ö.D. & Ö.D. \\
\hline $\mathrm{P}$ & 0.2345 & 0.2345 & 0.3394 & 0.2397 & 0.2536 \\
\hline \multicolumn{6}{|l|}{ Uygulama Şekli } \\
\hline Yapraktan & $8145 a^{*}$ & $407.3 \mathrm{a}$ & $19.48 \mathrm{a}$ & $14.10 \mathrm{a}$ & $274.8 \mathrm{a}$ \\
\hline Topraktan & $6086 b$ & $304.3 \mathrm{~b}$ & $16.64 \mathrm{~b}$ & $12.46 \mathrm{~b}$ & $208.2 \mathrm{~b}$ \\
\hline LSD \%5 & 596 & 29.8 & 1.05 & 0.73 & 22.6 \\
\hline$P$ & $<0.0001$ & $<0.0001$ & $<0.0001$ & 0.0003 & $<0.0001$ \\
\hline \multicolumn{6}{|l|}{ İnteraksiyon } \\
\hline LSD \%5 & 1192 & 59.6 & Ö.D. & 1.46 & Ö.D. \\
\hline$P$ & $<0.0001$ & $<0.0001$ & 0.9581 & 0.0034 & 0.1252 \\
\hline
\end{tabular}

\footnotetext{
*: Aynı sütun içerisinde farklı harflerle gösterilen ortalamalar arasında istatistiki farklılık bulunmaktadır, P $\leq 0.05$, Ö.D.: Önemli Değil
} 
Organik ve organomineral gübre uygulamalarının yüz tane ağırlığı, hacmi, tane uzunluğu ve büyüklüğü üzerine etkisinin önemli olmadığı, tane genişliğinde ise etkinin önemli olduğu saptanmıştır. Uygulama şekline göre değerlendirmede, tane genişliğindeki farklılıklar önemli bulunmaz iken yüz tane ağırlığı, yüz tane hacmi, tane uzunluğu ve büyüklüğünde en yüksek değerlerin (sırasıyla, $530.3 \mathrm{~g}, 497 \mathrm{~mL}, 25.82 \mathrm{~mm}$ ve $467.8 \mathrm{~mm}^{2}$ ) yapraktan yapılan uygulamalardan alındığı görülmektedir (Çizelge 2). Tangolar ve ark. (2007) da Çiloreş üzüm çeşidinde topraktan uygulanan organik materyallerin verim, salkım ve tane özellikleri üzerine etkisini önemli bulmamışlardır.

Çizelge 2. Organik ve organomineral gübre uygulamalarının Black Magic üzüm çeşidinin tane özellikleri üzerine etkisi Table 2. The effect of organic and organomineral fertilizer applications on berry characteristics of Black Magic grape variety

\begin{tabular}{|c|c|c|c|c|c|}
\hline Uygulama & $\begin{array}{l}\text { Yüz Tane Ağırlığı } \\
\text { (g) }\end{array}$ & $\begin{array}{l}\text { Yüz Tane Hacmi } \\
(\mathrm{mL})\end{array}$ & $\begin{array}{l}\text { Tane } \\
\text { Uzunluğu (mm) }\end{array}$ & $\begin{array}{l}\text { Tane Genişliği } \\
(\mathrm{mm})\end{array}$ & Tane Büyüklüğü \\
\hline \multicolumn{6}{|l|}{ Gübre } \\
\hline Kontrol & 503.8 & 474 & 25.62 & $18.24 a b$ & 467.4 \\
\hline Organik & 485.0 & 457 & 25.49 & $17.82 a b$ & 454.4 \\
\hline Organomineral & 484.4 & 454 & 25.28 & $17.75 \mathrm{~b}$ & 448.8 \\
\hline Organik+Organomineral & 487.4 & 451 & 25.36 & $18.25 \mathrm{a}$ & 463.4 \\
\hline LSD \%5 & Ö.D. & Ö.D. & Ö.D. & 0.49 & Ö.D. \\
\hline$P$ & 0.4824 & 0.3267 & 0.7288 & 0.0853 & 0.2966 \\
\hline \multicolumn{6}{|l|}{ Uygulama Şekli } \\
\hline Yapraktan & $530.3 a^{*}$ & $497 a$ & $25.82 \mathrm{a}$ & 18.11 & $467.8 \mathrm{a}$ \\
\hline Topraktan & $449.9 \mathrm{~b}$ & $420 \mathrm{~b}$ & $25.05 b$ & 17.93 & $449.1 \mathrm{~b}$ \\
\hline LSD \%5 & 21.2 & 20 & 0.49 & Ö.D. & 15.6 \\
\hline $\mathrm{P}$ & $<0.0001$ & $<0.0001$ & 0.0046 & 0.2882 & 0.0226 \\
\hline \multicolumn{6}{|l|}{ İnteraksiyon } \\
\hline LSD \%5 & 42.4 & 40 & 0.98 & Ö.D. & 31.2 \\
\hline$P$ & $<0.0001$ & $<0.0001$ & 0.0127 & 0.1726 & 0.0277 \\
\hline
\end{tabular}

*: Aynı sütun içerisinde farklı harflerle gösterilen ortalamalar arasında istatistiki farkııık bulunmaktadır, P $\leq 0.05$, Ö.D.: Önemli Değil

Çizelge 3. Organik ve organomineral gübre uygulamaların Black Magic üzüm çeşidinin şıra özellikleri üzerine etkisi Table 3. The effect of organic and organomineral fertilizer applications on must characteristics of Black Magic grape variety

\begin{tabular}{|c|c|c|c|c|}
\hline Uygulama & SÇKM (\%) & Asitlik (\%) & $\mathrm{pH}$ & Olgunluk İndisi \\
\hline \multicolumn{5}{|l|}{ Gübre } \\
\hline Kontrol & $16.87 b^{*}$ & $0.428 \mathrm{a}$ & $3.43 \mathrm{~b}$ & $39.46 \mathrm{c}$ \\
\hline Organik & $17.37 \mathrm{ab}$ & $0.403 \mathrm{~b}$ & $3.45 b$ & $43.16 \mathrm{~b}$ \\
\hline Organomineral & $17.63 \mathrm{a}$ & $0.397 b$ & $3.49 \mathrm{~b}$ & $45.03 \mathrm{ab}$ \\
\hline Organik+Organomineral & $17.48 \mathrm{a}$ & $0.368 c$ & $3.58 \mathrm{a}$ & $48.24 \mathrm{a}$ \\
\hline LSD \%5 & 0.61 & 0.021 & 0.08 & 3.49 \\
\hline $\mathrm{P}$ & 0.0865 & 0.0003 & 0.0114 & 0.0008 \\
\hline \multicolumn{5}{|l|}{ Uygulama Şekli } \\
\hline Yapraktan & $16.86 \mathrm{~b}$ & $0.419 a$ & $3.45 b$ & $40.34 \mathrm{~b}$ \\
\hline Topraktan & $17.82 \mathrm{a}$ & $0.379 \mathrm{~b}$ & $3.53 \mathrm{a}$ & $47.60 \mathrm{a}$ \\
\hline LSD \%5 & 0.43 & 0.015 & 0.05 & 2.47 \\
\hline$P$ & 0.003 & $<0.0001$ & 0.0090 & $<0.0001$ \\
\hline \multicolumn{5}{|l|}{ İnteraksiyon } \\
\hline LSD \%5 & 0.87 & 0.030 & 0.11 & 4.94 \\
\hline $\mathrm{P}$ & 0.0238 & 0.0058 & 0.0171 & 0.0063 \\
\hline
\end{tabular}

*: Aynı sütun içerisinde farklı harflerle gösterilen ortalamalar arasında istatistiki farkılık bulunmaktadır, $\mathrm{P} \leq 0.05$

Farklı gübre uygulamalarının şıra özellikleri üzerine etkisi istatistiksel olarak önemli bulunmuştur (Çizelge 3). Farklı gübre uygulamalarının etkisi incelendiğinde en yüksek SÇKM değerlerini, organomineral (\% 17.63) ve organik+organomineral (\% 17.48); Asitlik değerini Kontrol (\% 0.428); pH değerini organik+organomineral 
(3.58) ve olgunluk Indisi değerini ise organik+organomineral (48.24) uygulamasının verdiği saptanmıştır. Uygulama şekillerinin etkisi bakımından yapılan değerlendirmede ise en yüksek SÇKM (\% 17.82), $\mathrm{pH}$ (3.53) ve olgunluk indisi (47.60) değerleri topraktan yapılan gübrelemelerde; asitlik değeri (\% 0.419) ise yapraktan yapılan gübrelemelerde belirlenmiştir (Çizelge 3). Tangolar ve ark. (2007) da çalışmalarında Çiloreş üzüm çeşidine uygulanan organik gübrelerin SÇKM ve asitlik üzerine etkisini önemli bulmuşlardır.

Çizelge 4. Organik ve organomineral gübre uygulanan Black Magic üzüm çeşidinde SPAD analiz sonuçları Table 4. SPAD analysis results of Black Magic grape variety with organic and organomineral fertilizers

\begin{tabular}{llll}
\hline Uygulama & Tam Çiçek & Ben Düşme & Olgunluk \\
& 14.05 .2019 & 26.06 .2019 & 12.07 .2019 \\
\hline Gübre & & & \\
$\quad$ Kontrol & 27.4 & 31.7 & 33.4 \\
Organik & 26.8 & 31.0 & 32.1 \\
$\quad$ Organomineral & 26.8 & 30.8 & 32.0 \\
$\quad$ Organik+Organomineral & 25.4 & 30.7 & 31.3 \\
LSD \%5 & O.D. & Ö.D. & O.D. \\
$P$ & 0.4632 & 0.8141 & 0.5527 \\
\hline Uygulama Şekli & & & \\
$\quad$ Yapraktan & 27.0 & 32.0 a* & 32.7 \\
$\quad$ Topraktan & 26.1 & $30.2 \mathrm{~b}$ & 31.7 \\
LSD \%5 & O.D. & 1.7 & Ö.D. \\
P & 0.3494 & 0.0374 & 0.3563 \\
\hline Interaksiyon & & & \\
LSD \%5 & Ö.D. & Ö.D. & Ö.D. \\
P & 0.6675 & 0.2791 & 0.3304 \\
\hline
\end{tabular}

*: Aynı sütun içerisinde farklı harflerle gösterilen ortalamalar arasında istatistiki farklılık bulunmaktadır, P $\leq 0.05$, Ö.D.: Önemli Değil

Çizelge 5. Organik ve organomineral gübre uygulamaların Black Magic üzüm çeşidinin yaprak sıcaklığı üzerine etkisi Table 5. The effect of organic and organomineral fertilizer applications on leaf temperature of Black Magic grape variety

\begin{tabular}{|c|c|c|c|}
\hline Uygulama & $\begin{array}{l}\text { Tam Çiçek } \\
\text { 14.05.2019 }\end{array}$ & $\begin{array}{l}\text { Ben Düşme } \\
25.06 .2019\end{array}$ & $\begin{array}{l}\text { Olgunluk } \\
16.07 .2019\end{array}$ \\
\hline \multicolumn{4}{|l|}{ Gübre } \\
\hline Kontrol & 31.4 & $34.6 a^{*}$ & 33.8 \\
\hline Organik & 31.7 & $33.0 \mathrm{~b}$ & 33.5 \\
\hline Organomineral & 33.0 & $34.2 \mathrm{ab}$ & 34.4 \\
\hline Organik+Organomineral & 31.7 & $33.5 \mathrm{ab}$ & 32.7 \\
\hline LSD \%5 & Ö.D. & 1.5 & Ö.D. \\
\hline $\mathrm{P}$ & 0.4851 & 0.1229 & 0.2920 \\
\hline \multicolumn{4}{|l|}{ Uygulama Şekli } \\
\hline Yapraktan & 31.9 & 33.9 & 34.0 \\
\hline Topraktan & 32.0 & 33.8 & 33.2 \\
\hline LSD \%5 & Ö.D. & Ö.D. & Ö.D. \\
\hline $\mathrm{P}$ & 0.8177 & 0.8813 & 0.1661 \\
\hline \multicolumn{4}{|l|}{ İnteraksiyon } \\
\hline LSD \%5 & Ö.D. & Ö.D. & Ö.D. \\
\hline$P$ & 0.9515 & 0.1931 & 0.8082 \\
\hline
\end{tabular}

*: Aynı sütun içerisinde farklı harflerle gösterilen ortalamalar arasında istatistiki farklılık bulunmaktadır, P $\leq 0.05$, Ö.D.: Önemli Değil 


\section{Ekofizyolojik bulgular}

Uygulanan organik ve organomineral gübrelerin yaprak klorofil miktarı üzerine etkisi tam çiçeklenme (14.05.2019), ben düşme (26.06.2019) ve olgunluk (12.07.2019) dönemlerinde yapılan ölçümlerde istatistiksel olarak önemli bulunmamıştır (Çizelge 4). Uygulama şeklinin klorofil miktarı üzerine etkisi tam çiçeklenme ve olgunluk dönemlerinde önemli bulunmazken, farklılığın ben düşme döneminde önemli olduğu görülmüştür.

Yapraktan yapılan gübrelemelerden daha yüksek SPAD değeri (32.0) elde edilmiştir. Zengin (2019) Asma anaçlarına sentetik ve organik malç uygulamalarının klorofil miktarı üzerine etkisinin istatistiksel olarak önemli çıkmadığını belirlemiştir.

Farklı gübre uygulamalarının infrared termometre ile ölçülen yaprak sıcaklıkları üzerine etkisinin tam çiçeklenme (14.05.2019) ve olgunluk (16.07.2019) dönemlerinde önemsiz; ben düşme (25.06.2019) döneminde önemli olduğu saptanmıştır. Bu dönemde ölçülen en yüksek değer $\left(34.6^{\circ} \mathrm{C}\right)$ kontrol uygulamasından alınmıştır. Yaprak sıcaklığı üzerine uygulama şeklinin etkisi istatistiksel olarak önemli çıkmamıştır (Çizelge 5). Küçükbasmacı (2019) farklı sulama seviyeleri ile sulanan Prima üzüm çeşidinde uygulamaların taç yüzey sıcaklığı üzerine belirgin etkisinin olmadığını belirlemiştir.

\section{Bitki beslemeyle ilgili bulgular}

Organik ve organomineral gübreler ile uygulama şekillerinin yaprakların makro ve mikro element konsantrasyonu üzerine etkisi istatistiksel olarak önemli bulunmamıştır (Çizelge 6). Oysaki Ahmed ve ark. (2018) Sakki hurma çeşidinde yaptıkları çalışmada sığır ve koyun gübresinin mineral NPK ile kombine edilerek kullanılan bitkilerinin meyvesinde tek başına organik gübre uygulananlardan daha yüksek $\mathrm{N}, \mathrm{P}$ ve $\mathrm{K}$ konsantrasyonu belirlemişlerdir.

Çizelge 6. Organik ve organomineral gübre uygulamalarının Black Magic üzüm çeşidinin bitki besin elementi içeriğine etkisi

Table 6. The effect of organic and organomineral fertilizer applications on the plant nutrient content of Black Magic grape variety

\begin{tabular}{|c|c|c|c|c|c|c|c|c|c|c|}
\hline \multirow{2}{*}{\multicolumn{2}{|c|}{ Uygulama }} & \multicolumn{5}{|c|}{ Makro elementler (\%) } & \multicolumn{4}{|c|}{ Mikro elementler $\left(\mathrm{mg} \mathrm{kg}^{-1}\right)$} \\
\hline & & $\mathrm{N}$ & $\mathrm{P}$ & $\mathrm{K}$ & $\mathrm{Ca}$ & $\mathrm{Mg}$ & $\mathrm{Fe}$ & $\mathrm{Zn}$ & $\mathrm{Mn}$ & $\mathrm{Cu}$ \\
\hline \multicolumn{11}{|l|}{ Gübre } \\
\hline \multicolumn{2}{|l|}{ Kontrol } & 2.39 & 0.16 & 0.40 & 2.71 & 0.53 & 92 & 11.9 & 90 & 11.0 \\
\hline \multicolumn{2}{|l|}{ Organik } & 2.39 & 0.18 & 0.48 & 2.81 & 0.52 & 116 & 13.5 & 83 & 10.7 \\
\hline \multicolumn{2}{|c|}{ Organomineral } & 2.35 & 0.18 & 0.38 & 2.57 & 0.51 & 113 & 12.9 & 80 & 11.7 \\
\hline \multicolumn{2}{|c|}{ Organik+Organomineral } & 2.39 & 0.16 & 0.47 & 2.55 & 0.50 & 91 & 10.9 & 96 & 8.9 \\
\hline \multicolumn{2}{|l|}{ LSD \%5 } & Ö.D. & Ö.D. & Ö.D. & Ö.D. & Ö.D. & Ö.D. & Ö.D. & Ö.D. & Ö.D. \\
\hline \multicolumn{2}{|l|}{$\mathrm{P}$} & 0.9811 & 0.2766 & 0.5763 & 0.2944 & 0.9871 & 0.4523 & 0.4875 & 0.5176 & 0.3238 \\
\hline \multicolumn{11}{|c|}{ Uygulama Şekli } \\
\hline \multicolumn{2}{|l|}{ Yapraktan } & 2.46 & 0.17 & 0.37 & 2.60 & 0.51 & 108 & 12.6 & 91 & 10.3 \\
\hline \multicolumn{2}{|l|}{ Topraktan } & 2.30 & 0.16 & 0.50 & 2.71 & 0.52 & 98 & 12.0 & 83 & 10.8 \\
\hline \multicolumn{2}{|l|}{ LSD \%5 } & Ö.D. & Ö.D. & Ö.D. & Ö.D. & Ö.D. & Ö.D. & Ö.D. & Ö.D. & Ö.D. \\
\hline \multicolumn{2}{|l|}{$P$} & 0.0596 & 0.2163 & 0.0507 & 0.3358 & 0.9607 & 0.5114 & 0.629 & 0.3393 & 0.6987 \\
\hline \multicolumn{11}{|c|}{ İnteraksiyon } \\
\hline \multicolumn{2}{|c|}{ LSD \%5 } & Ö.D. & Ö.D. & Ö.D. & Ö.D. & Ö.D. & Ö.D. & Ö.D. & Ö.D. & Ö.D. \\
\hline \multicolumn{2}{|l|}{$P$} & 0.3139 & 0.0792 & 0.5205 & 0.0958 & 0.7958 & 0.3564 & 0.6488 & 0.5331 & 0.3534 \\
\hline \multirow{3}{*}{$\begin{array}{l}\text { Sinır } \\
\text { Değerlerix }\end{array}$} & Noksan & $1.50-1.99$ & $<0.15$ & $1.00-1.29$ & $1.50-1.99$ & $<0.30$ & $<40$ & $18-24$ & $<30$ & $3-4$ \\
\hline & Yeterli & $2.00-2.40$ & $0.15-0.50$ & $1.30-1.40$ & $2.00-2.50$ & $0.30-1.50$ & $40-300$ & $25-100$ & $30-150$ & $5-50$ \\
\hline & Fazla & $>2.40$ & $>0.50$ & $>1.40$ & $>2.50$ & $>1.50$ & $>300$ & $>100$ & $>150$ & $>50$ \\
\hline
\end{tabular}

x: Sınır Değerleri (Jones ve ark., 1991), P $\leq 0.05$, Ö.D.: Önemli Değil

\section{Sonuçlar}

Sürdürülebilir tarım uygulamalarında, bitkisel üretimde verimlilik ve kaliteyi artırmak amacının yanında toprak yapısı, yer altı su kaynakları ve çevreyi koruma hedeflenmektedir. Bu hedeflere ulaşmak için öncelikle toprağın organik maddesi ve besin içeriğinin arttırılması gereklidir. Topraklarımızın organik madde miktarını artırmak için kullanılabilecek organik madde kaynaklarına intiyaç duyulmaktadır. Ancak bu organik maddeler bitkilerin beslenmesi ve veriminde çok belirgin bir atışa neden olmamaktadırlar. Bu çalışma sonucu genel olarak değerlendirildiğinde gübre uygulama şeklinin önemli, gübre çeşidinin önemsiz olduğu saptanmıştır. Kesin yargıya varabilmek için çalışmanın devam eden yıllarda da sürdürülmesinin uygun olacağı kanısına varılmıştır. Çalışma sonucunda 
denemede kullanılan Black Magic çeşidinde incelenen bazı özellikler bakımından olumlu sonuçlar alınmıştır. Gübrelerin özellikle yaprak besin elementi üzerine etkilerinde bir miktar iyileşme görülmesi, etkinin sonraki yıllarda da süreceğinin işaretleri olarak görülmüştür

\section{ÖZET}

Amaç: Bu çalışma, $1103 \mathrm{P}$ asma anacı üzerine aşılı Black Magic üzüm çeşidine organik ve organomineral sıvı gübrelerin verim, kalite ve bitki beslemeye etkilerini belirlemek amacıyla planlanmıştır.

Yöntem ve Bulgular: Çalışmada yapraktan ve topraktan olmak üzere organik (BioGas, sırasıyla, $400 \mathrm{cc} 100 \mathrm{~L}^{-1}$ ve $4 \mathrm{~L} \mathrm{da}^{-1}$ ) ve organomineral (AminoSEL-K, sırasıyla, $300 \mathrm{cc}$ $100 \mathrm{~L}^{-1}$ ve $4 \mathrm{~L} \mathrm{da}^{-1}$ ) gübre uygulamaları ayrı ayrı ve birlikte yapılmıştır. Araştırma sonucunda verim ve salkım ağırlığı ile bitki besleme üzerine gübre uygulamalarının etkisi önemli çıkmamış, şıra özellikleri üzerine etki önemli bulunmuştur. En yüksek Suda Çözünebilir Kuru Madde değeri, organomineral (\% 17.63) ve organik+organomineral (\% 17.48) uygulamalarından elde edilmiştir. Çalışmada uygulama şeklinin önemli olduğu saptanmıştır. En yüksek verim ve salkım ağırlığı (sırasıyla, $8145 \mathrm{~g}$ ve $407.3 \mathrm{~g}$ ) yapraktan yapılan uygulamalardan elde edilmiştir.

Genel Yorum: Sonuç olarak gübreler ve uygulama şekli konusunda kesin yargıya varabilmek için çalışmanın devam eden yıllarda da sürdürülmesinin uygun olacağı kanısına varılmıştır.

Çalışmanın Önemi ve Etkisi: Çalışmada kullanılan sıvı organik ve organomineral gübrelerin yapraktan uygulanmasıyla üzüm verimi ve kalitesi üzerine etkilerinin ilk yıldan itibaren görülebileceği, devam eden yıllarda da etkinin artarak devam edeceği görüşü oluşmuştur.

Anahtar Kelimeler: Asma, gübreleme, bitki besleme, ekolojik bağcllık.

\section{TEŞEKKÜR}

Bu çalışma, Çukurova Üniversitesi Bilimsel Araştırma Projeleri Koordinasyon Birimi tarafından (Proje No: FYL2019-11584) desteklenmiştir.

\section{ÇIKAR ÇATIŞMA BEYANI}

Makale yazarları aralarında herhangi bir çıkar çatışması olmadığını beyan ederler.

\section{ARAŞTIRMACILARIN KATKI ORANI BEYANI}

Yazarlar makaleye eşit oranda katkı sağlamış olduklarını beyan ederler.

\section{KAYNAKLAR}

Ahmed MA, Kassem HA, Al-Obeed RS (2018) Effect of organo-mineral fertilizers on Sakki date palm "Phoenix dactylifera L." fruits yield, quality and nutritional value. Bothalia Journal 43(11): 103-116.

Aslan N (2018) Organomineral gübre kullanımının antepfıstığı verimi ve toprağın fiksasyon kapasitesi üzerine etkisi, In: Organomineral Gübre Çalıştayı, Bildiriler Kitabı (Ed. Kınacı E), 1. Baskı, Sena Ofset Ambalaj Matbaacılık, İstanbul. s. 192-200.

Aygün S, Özdemir G (2019) Organik ve konvansiyonel yöntemlerle yetiştirilen üzüm çeşitlerinin verim ve kalite yönünden karşılaştırılması. International Engineering and Natural Sciences Conference (IENSC 2019), Kasım 6-8, Diyarbakır, Türkiye. pp. 1196-1203.

Bremner JM (1965) Total Nitrogen, In: Methods of soil analysis. Part 2: Chemical and microbial properties (Ed. Black CA), Number 9 in series Agronomy. American Society of Agronomy, Inc. Publisher, Madison, USA. pp. 1049-1178.

Dannehl D, Becker C, Suhl J, Josuttis M, Schmidt U (2016) Reuse of organomineral substrate waste from hydroponic systems as fertilizer in open-field production increases yields, flavonoid glycosides, and caffeic acid derivatives of red oak leaf lettuce (Lactuca sativa L.) Much more than synthetic fertilizer. J. Agri. Food Chem. 64: 7068-7075.

Erdal, i. 2018. Türkiye'de organomineral gübrelerin kullanıldığı araştırma çalışmaları ve elde edilen sonuçlar. In: Organomineral Gübre Çalıştayı, Bildiriler Kitabı (E. Kınacı editör). Sena Ofset Ambalaj Matbaacılık, İstanbul, 156-165.

Erdal Ü, Sökmen Ö, Üner K, Bilir L, Göçmez S, Okur N, Okur B, Anaç D, Ongun AR, Ertem A, Çakmak R (2010) Bağ yetiştiriciliğinde organik ve konvansiyonel tarım uygulamalarının verim, kalite ve toprak özellikleri üzerine etkileri, In: Organik Tarım Araştırma Sonuçları 2005-2010 (Ed. Alay Vural A), T.C. Tarım ve Köyişleri Bakanlığı, Ankara, Turkey. pp. 333-340. https://orgprints.org/22128/

Fernandes ALT, Rodrigues GP, Testezlaf R (2003) Mineral and organomineral fertirrigation in felation to quality of greenhouse cultivated melon. Scientia Agricola 60(1): 149-154.

IIlter E, Altındişli A (1996) Ekolojik Tarım ve ilkeleri. Ekolojik (Organik, Biyolojik) Tarım. Ekolojik Tarım Organizasyonu Derneği (ETO). Bornova-izmir. s. 1-6. 
Jones JB, Wolf JrB, Mills HA (1991) Plant Analysis Handbook. Micro-Macro publishing. Inc., USA. p. 1213.

Kacar B (1972) Bitki ve Toprağın Kimyasal Analizleri. II. Bitki Analizleri. Ankara Üniversitesi Ziraat Fakültesi Yayınları 453, Uygulama Kılavuzu 155, Ankara Üniversitesi Basımevi, Ankara.

Kacar B, Taban S, Kütük CA (1996) Çay atıklarının zenginleştirilmiş organik gübreye dönüştürülerek kullanılması. Araştırma Geliştirme Uygulama Projesi, Çay İşletmeleri Genel Müdürlüğü, Rize.

Kaptan MA, Aydın M (2018) Pamuk üretiminde üst üste iki yıl farklı dozlarda humik madde kullanımının temel toprak özellikleri üzerine etkisi, In: Organomineral Gübre Çalıştayı, Bildiriler Kitabı (Ed. Kınacı E), 1. Baskı, Sena Ofset Ambalaj Matbaacılık, İstanbul. s. 118-127.

Kominko H, Gorazda K, Wzorek Z (2016) The possibility of organo-mineral fertilizer production from sewage sludge. Waste Biomass Valor. 8: 1781-1791.

Küçükbasmacı AÖ (2019) Farklı asma anaçları üzerine aşılı Prima sofralık üzüm çeşidinin kısıntılı sulama koşullarına tepkileri. Yüksek Lisans Tezi, Selçuk Üni., Fen Bil. Ens., Bahçe Bitkileri ABD, $53 \mathrm{~s}$.

Olaniyi JO, Akanbi, WB (2007) Effect of organo mineral and inorganic fertilizers on the yield quality of fluted pumpkin (Telfaria occidentalis Hook. F.). African Crop Science Conference Proceedings, 8: 347-350.

Olaniyi JO, Ogunbiyi EM, Alagbe DD (2009) Effects of organo-mineral fertilizers on growth, yield and mineral nutrients uptake in cucumber. J. Animal and Plant Sci. 5(1): 437-442.

Olaniyi JO, Akanbi WB, Olaniran OA, Ilupeju OT (2010) The effect of organo-mineral and inorganic fertilizers on the growth, fruit yield, quality and chemical compositions of Okra. J. Animal and Plant Sci. 9(1): 1135-1140.

Olaniyi JO, Ojetayo AE (2011) Effect of fertilizer types on the growth and yield of two cabbage varieties. J. Animal and Plant Sci. 12(2): 1573-1582.

Ojo JA, Olowoake AA, Obembe A (2014) Efficacy of organomineral fertilizerand un-amended compost on the growth and yield of watermelon (Citrullus lanatus Thumb) in ilorin Southern Guinea Savanna zone of Nigeria. Int. J. Recycl. Org. Waste Agricult. 3: 121-125.

Özdemir G (2018) Organik ve organomineral gübre uygulamalarının Öküzgözü ve Boğazkere üzüm çeşitlerinin sürgün gelişimi üzerine etkilerinin belirlenmesi. International Congress on Agriculture and Animal Sciences, Kasım 7-9, Alanya, Türkiye. Proceeding Book, 821-827p.
Özdemir G, Kitir N, Turan M, Özlü E (2018) Impacts of organic and organo-mineral fertilizers on total phenolic, flavonoid, anthocyanin and antiradical activity of Okuzgozu (Vitis vinifera L.) grapes. Acta Sci. Pol. Hortorum Cultus 17(3): 91-100.

Pekcan T, Turan HS, Çolakoğlu H (2009) Effects of organomineral, mineral and farmyard manures on the yield and quality of olive trees (Olea europaea L.). The Proceedings of the International Plant Nutrition Colloquium XVI, Department of Plant Sciences, UC Davis, UC Davis. 26-30 August 2009, California, USA. https://escholarship.org/uc/item/ 38303984.

Rotaru L, Stoleru V, Mustea M (2011) Fertilization with green manure on Chasselas Doré grape vine as an alternative for sustainable viticulture. J. Food, Agri. Environ. 9(3/4 part 1): 236-243.

Süzer S, Çulhacı E (2017) Farklı organomineral ve inorganik kompoze gübrelerin kışlık ekmeklik buğday tane verimi ve bazı verim unsurları üzerine etkileri. Toprak Bil.ve Bitki Besleme Derg. 5(2): 87-92.

Tamer N, Namlı A (2018) Organik ve organomineral gübrelerin toprağın enzim aktivitesi ile buğday verimi üzerine etkileri, In: Organomineral Gübre Çalıştayı, Bildiriler Kitabı (Ed. Kınacı E), 1. baskı, Sena Ofset Ambalaj Matbaacilık, İstanbul. s. 81-96.

Tangolar S, Özdemir G, Gürsöz S, Çakır A, Gök Tangolar $S$ (2007) Bazı organik gübre uygulamalarının asmanın (Vitis vinifera L. Çiloreş) fenolojik gelişmesi ile salkım, tane ve şıra özellikleri üzerine etkisi. Akdeniz Üni. Zir. Fak. Derg. 20(2): 319-325.

Tangolar S, Kaya Z., Tangolar SG, Ekbiç HB, Maden A (2011) Ekolojik bağcılığın Adana koşullarında uygulanabilirliğinin araştırılması. Türkiye VI. Ulusal Bahçe Bitkileri Kongresi. Ekim 4-8, Şanlıurfa. 128-134

Tangolar S, Tangolar S, Alkan Torun A, Ada M, Aydın O (2019) Bağ toprağına uygulanan organik materyallerin verim, kalite ve besin elementleri alımına etkisi. Mediterranean Agri. Sci. 32(Özel sayı): 135-140.

Tarakçıŏlu C, Aşkın T (2006) Organomineral gübrenin kivi bitkisinin verim ile yapraklarının besin maddesi içerikleri üzerine etkisi. II. Ulusal Üzümsü Meyveler Sempozyumu, Eylül 14-16, Tokat. 267-272s.

Zengin H (2019) Farklı malç uygulamalarının bazı asma anaçlarının gelişimi üzerine etkileri. Yüksek Lisans Tezi, Selçuk Üni. Fen Bil. Ens., Bahçe Bitkileri ABD. 52 s. 